\title{
PARA ONDE FORAM OS SINDICATOS? Do sindicalismo de confronto ao sindicalismo negocial
}

\author{
Ricardo Antunes* \\ Jair Batista da Silva**
}

\begin{abstract}
O objetivo deste artigo é indicar elementos para a seguinte indagação: para onde foram os sindicatos? Para tanto, analisamos as duas principais centrais sindicais do país: a Central Única dos Trabalhadores (CUT) e a Força Sindical (FS), tanto em seu ideário quanto em relação às suas respectivas atuações sindicais. Nossa hipótese central é que o sindicalismo brasileiro recente, denominado como novo sindicalismo, sofreu grandes transformações ao longo de mais de três décadas, que acabaram por alterar significativamente suas práticas e concepções sindicais. Isso se verificou especialmente em seu núcleo mais importante, a CUT, resultante direta do novo sindicalismo, cuja atuação sindical distanciou-se do chamado sindicalismo combativo, dotado de claro caráter de classe, para práticas sindicais predominantemente voltadas para as negociações visando à ampliação dos espaços de cidadania. Para realizar esta análise nosso trabalho recorreu às principais resoluções de congressos, plenárias, documentos e às pesquisas que analisaram as práticas sindicais durante as décadas mais recentes.
\end{abstract}

Palavras-chavE: Ação sindical. Centrais sindicais. Novo sindicalismo. Sindicalismo negocial. CUT. Força Sindical.

\section{INTRODUÇÃO}

O objetivo deste artigo é compreender as mutações que vêm ocorrendo nos organismos de representação da classe trabalhadora, particularmente as transformações experimentadas pelas principais centrais sindicais, visando oferecer uma resposta inicial à indagação que motiva este texto: para onde foram os sindicatos?

Para indicar algumas respostas que particularizam o caso brasileiro, vamos procurar compreender, em linhas mais gerais, quais foram os ideários e as principais ações desencadeadas pelas duas principais centrais sindicais que atuaram - e atuam - no Brasil recente: a Central Única dos Trabalhadores (CUT) e a Força Sindical (FS). Esta análise tem como pano de fundo o contexto econômico, político e sindical que remete aos ciclos das lutas e ações sindicais travadas nas últimas décadas no Brasil.

\footnotetext{
* Universidade Estadual de Campinas (UNICAMP). Instituto de Filosofia e Ciências Humanas (IFCH).r

Barão Geraldo. Cep: 13083-970. Campinas - São Paulo Brasil. Caixa-postal: 6110. rantunes@unicamp.br

** Universidade Federal da Bahia (UFBA). Faculdade de Filosofia e Ciências Humanas (FFCH).

Estrada de São Lázaro. Federação. Cep: 40210730. Salvador - Bahia - Brasil. jabs222@gmail.com
}

Para esboçar uma resposta preliminar à questão, parece-nos adequado partir da seguinte hipótese: o sindicalismo brasileiro recente (ou novo sindicalismo, como se consagrou na bibliografia especializada) vem se transformando de modo acentuado; inaugurado pelas greves de 1978, bem como pelas primeiras articulações sindicais que se desenvolviam desde meados daquela década, o novo sindicalismo promoveu mudanças significativas na cultura sindical e política brasileira ao instituir novas práticas, mecanismos e instituições. Gradativamente, entretanto, ao longo de mais de três décadas, suas práticas cotidianas de acentuada (ainda que não exclusivamente) tendência confrontacionista - foram sendo substituídas por uma nova pragmática sindical predominantemente negocial, onde o confronto cedia espaço para as parcerias, negociações e incentivo aos pactos sindicais etc. (Antunes, 2013; Antunes e Santana, 2014; Silva, 2008; 2013).

O desdobramento desta mutação vem consolidando entre nós uma prática sindical que, para além de fetichizar a negociação, transforma os dirigentes em novos gestores que encontram na estrutura sindical mecanismos 
e espaços de realização, tais como operar com fundos de pensão, planos de pensão e de saúde, além das inúmeras vantagens intrínsecas ao aparato burocrático típico do sindicalismo de estado vigente no Brasil desde a década de 1930. Isto alterou o perfil das lideranças e das práticas sindicais adotadas até então. Tais mudanças também alteraram o destinatário do discurso sindical, cujo ideário vai paulatinamente se deslocando de um sindicalismo de classe para um sindicalismo cidadão (Silva, 2008; Antunes, 1995; J. Rodrigues, 1997; Rodrigues, 1993)

Sabemos que estas mutações e metamorfoses nas práticas sindicais ocorreram ao longo da um período expressivo da ação da classe trabalhadora e suas formas de organização no Brasil. Ao longo dos anos 1980, por exemplo, nosso país esteve à frente das lutas sociais e sindicais, mesmo quando comparado com outros países avançados dotados de ampla experiência sindical. A criação do PT em 1980, da CUT em 1983, do MST em 1984, a luta pelas eleições diretas em 1985, a eclosão de quatro greves gerais ao longo da década, a campanha pela Constituinte e a promulgação da nova Constituição em 1988 e, finalmente, as eleições diretas de 1989, são exemplos vivos da força das lutas daquela década. ${ }^{1}$ Houve ـ avanços significativos na luta pela autonomia ثं e liberdade dos sindicatos em relação ao EsФิ tado, através do combate ao Imposto Sindical, à à estrutura confederacional, cupulista, hie$\stackrel{\infty}{\infty}$ rarquizada e atrelada (Antunes, 1982; Araújo, 1998; Vianna, 1976), instrumentos que se constituíam em alavancas utilizadas pelo Esis tado e as classes dominantes para controlar $\therefore$ os sindicatos e a classe trabalhadora. Aquela i década conformou, também, um quadro niti$\therefore$ damente favorável para o chamado novo sindicalismo, que caminhava em direção contrária à crise sindical presente em vários países capitalistas avançados.

Entretanto, no final da década de 1980

${ }^{1}$ Retomamos aqui várias ideias que estão apresentadas especialmente em Antunes e Santana, 2014. já começavam a despontar as tendências econômicas, políticas e ideológicas que foram responsáveis pela inserção do sindicalismo brasileiro na onda regressiva, resultado tanto da reestruturação produtiva em curso em escala global, como da emergência da pragmática neoliberal e da financeirização do capital, que passaram a exigir mudanças significativas no mundo do trabalho. Esta processualidade complexa trouxe fortes consequências também para os organismos representativos da classe trabalhadora. (Antunes, 2013; Antunes e Santana, 2014; Silva, 2008; 2009). Vamos indicar, então, como esse movimento ocorreu no interior das duas principais centrais sindicais do país, na CUT e na Força Sindical. Comecemos pela CUT.

\section{A CUT: a emergência do confronto, o avanço do sindicalismo propositi- vo e o culto da negociação}

Depois de mais de trinta anos da emergência do novo sindicalismo e da Central Única dos Trabalhadores (CUT), criada em 1983, já é possível fazer um balanço do que se passou nestes anos. Quais foram seus principais avanços e recuos? Sua prática sindical, três décadas depois de sua criação, consolidou mais rupturas ou acabou por acomodar-se ao sindicalismo de tipo mais tradicional? São perguntas que nosso texto busca elucidar ou, ao menos, indicar pontos para uma possível resposta.

É possível afirmar alusivamente que, entre as décadas de 1970 e 1980, um novo elemento começou a caracterizar o movimento sindical brasileiro existente durante a ditadura militar. O nosso movimento operário e sindical viveu em fins dos anos 1970 um momento de extrema importância para sua história. Após o duro impacto do golpe de 1964, que lhe havia deixado pouco espaço de ação - a não ser aqueles presentes no trabalho silencioso e cotidiano no interior das fábricas e de algumas tentativas pontuais de contestação (Antunes, 1992; Hum- 
phrey, 1982; Frederico, 1979) -, um sindicalismo de corte mais autêntico aflorava, exigindo a ampliação dos espaços para a representação dos interesses da classe trabalhadora que se expandiu enormemente durante estas décadas.

No cenário político mais amplo, a reemergência do movimento dos trabalhadores estremeceu os arranjos políticos da transição do fim da ditadura militar para o rearranjo civil que estava sendo articulado, excluindo o movimento sindical e dos trabalhadores, e atacava frontalmente a política econômica desenvolvida pela ditadura. (Silva, 2008; Santana, 1999; J. Rodrigues, 1997; Antunes, 1992 e 1995; Frederico, 1979).

Houve avanços significativos na luta pela autonomia e liberdade dos sindicatos em relação ao Estado, deu-se um combate à estrutura atrelada ao estado e ao Imposto Sindical, instrumentos utilizados para controlar os sindicatos. Conformou-se, também, um quadro nitidamente favorável para o chamado novo sindicalismo, que resistia fortemente, frente às tendência regressivas dominantes no cenário europeu e norte-americano, cujo sindicalismo se encontrava em um quadro crítico.

A intensificação da introdução de plantas industriais modernas e sua concentração geográfica (processo que se iniciou em fins dos anos 1950) possibilitou o surgimento do que se convencionou chamar de "nova classe operária”. Estavam sendo criadas, então, a partir do golpe de 1964, elementos que possibilitaram uma forte expansão do padrão de acumulação através do incremento da produção industrial, em gestação desde os anos 1950/1970, ampliando significativamente o novo proletariado industrial no Brasil, concentrado, particularmente, no cinturão industrial automotivo e metalúrgico do ABC paulista, onde estavam instaladas as grandes montadoras (Antunes, 1992; Humphrey, 1982; Almeida, 1975).

E essa forte expansão da classe trabalhadora, ao final dos anos 1970, constituiu-se na principal base social do novo sindicalismo que começava a florescer. Forjou-se um novo movimento sindical, cuja liderança de maior destaque era Luiz Inácio Lula da Silva, que encontrava capilaridade não só entre os trabalhadores industriais, como os metalúrgicos, mas, também, entre os assalariados rurais, como os chamados "boias-frias", os funcionários públicos e os setores assalariados médios urbanos que se "proletarizavam", como médicos e professores, dentre tantos outros contingentes do mundo do trabalho que se alteravam profundamente. O setor de serviços e a agricultura também gestavam novos assalariados que ampliavam a nossa classe trabalhadora, quando comparada àquela existente no pré-1964.

Fruto desta conjuntura, o novo sindicalismo surgiu da articulação de variadas concepções que se articulavam em torno da bandeira de um sindicalismo de classe, mais autônomo e independente em relação ao estado. Neste sentido, ele propunha uma ruptura com o passado, que teria sido predominantemente pautado pela "colaboração de classe", "reformismo", "conciliação", "cupulismo" etc., práticas às quais o novo sindicalismo se opunha fortemente. (Santana, 2001; 1999).

Sua corrente mais expressiva - o chamado novo sindicalismo - era oriundo da própria estrutura sindical. Agrupava vários líderes sindicais denominados "autênticos" (como Lula, Olívio Dutra, Jacó Bittar, dentre tantos outros) e que praticavam um sindicalismo que, de fato, se diferenciava do velho sindicalismo oficial. Essa tendência somou-se ao também importante movimento das oposições sindicais, buscando avançar em sua maior aspiração, que era criar uma nova central sindical autônoma, livre e independente do estado e do patronato.

Já em 1977, diversos setores e representantes da primeira vertente - os sindicalistas independentes - manifestam interesse em realizar um Congresso Nacional das Classes Trabalhadoras (CONCLAT). A oportunidade para realizar tal articulação ocorreu em 1978, no V Congresso da Confederação Nacional dos Trabalhadores na Indústria (CNTI). A união destes ativistas sindicais contra o presidente 
da entidade Ary Campista foi um ensaio de unidade e mobilização dos dirigentes sindicais mais ativos contra as lideranças acomodadas no interior das entidades e da estrutura sindical, o chamado peleguismo. Este ensaio de união permitiu a este grupo constituir uma identidade sindical própria, passando a intitular-se como "sindicalistas autênticos". Deste grupo faziam parte várias lideranças que se organizaram posteriormente para criar a CUT (Silva, 2008).

Outra força política importante, que contribuiu para a constituição da CUT foi o agrupamento organizado em torno das oposições sindicais. A expressão mais fortemente articulada deste grupo girava em torno do Movimento da Oposição Sindical Metalúrgica de São Paulo (MOMSP). Uma das primeiras iniciativas para reunir a oposição sindical ocorreu no congresso da MOMSP, realizado em São Paulo, em 1979. A finalidade era reunir, organizar e mobilizar as diferentes forças de esquerda que atuavam no movimento sindical e combatiam duramente tanto o peleguismo, como o reformismo sindical da esquerda tradicional que se articulava em torno do PCB (Silva, 2008; Antunes, 1995; Giannotti e Lopes Neto, 1991).

Ainda anteriormente à criação da CUT, a Associação Nacional dos Movimentos Populaฟ res e Sindicais (ANAMPOS) realizou congresФั sos nacionais, como o Encontro de Monlevade realizado em fevereiro de 1980 e o Encontro co de Goiânia em 1982. No primeiro encontro, foi aprovado o Documento de Monlevade, no qual foram estabelecidas as principais orientações is em direção à luta pela democratização da es\& trutura sindical, em conformidade com a Con๙ิ venção 87 da Organização Internacional do $\therefore$ Trabalho. O fim dos impedimentos jurídicos que restringiam o pleno direito de greve, além do direito de greve e da implantação da negociação direta entre trabalhadores e patrões, sem a mediação ou intervenção do Estado foram pontos de destaque nesta corrente sindical (Silva, 2008; Antunes, 1995; Costa, 1994;
Giannotti e Lopes Neto, 1991).

Deve-se sublinhar a importância dessa confluência, que foi decisiva para a criação da nova central. De um lado, as denominadas "lideranças autênticas" que já se apresentavam como expressão do novo sindicalismo. De outro lado, as oposições sindicais que se destacavam pelas lutas que travavam contra a estrutura sindical. Se o "Congresso de Poços de Caldas (MG) e o Congresso em Lins (SP) foram momentos embrionários do novo sindicalismo que questionou a prevalência da burocracia sindical sobre as entidades sindicais", de outra parte, "com eixos de ação diferenciados, realizou-se o Encontro Nacional das Oposições Sindicais e, posteriormente, o I Encontro Nacional de Trabalhadores em Oposição à Estrutura Sindical (ENTOES), que reafirmava o papel das oposições sindicais na luta contra o sindicato oficial (Silva, 2008; Antunes, 1995). Da ação convergente do novo sindicalismo e do movimento de oposição sindical caminhou-se, rapidamente, para a criação, no início dos anos oitenta, de uma central sindical de âmbito nacional" (Antunes, 1995, p. 45-46).

É deste rico movimento de fusão, comportando confluências e tensões, entre importantes correntes que praticavam um sindicalismo diferenciado do peleguismo, que nasceu a Central Única dos Trabalhadores (CUT). Criada nestes embates, no início da década de 1980, a CUT foi, por um lado, um vivo resultado deste esforço de unificação das lutas da classe trabalhadora. Mas foi, também, simultaneamente, a cristalização das diferenciações no interior do movimento sindical brasileiro, que se aprofundariam mais tarde.

A nova Central nasceu, portanto, da associação de diversas forças com tradições sindicais distintas - sindicalistas independentes, oposições sindicais, militantes da pastoral operária, setores da esquerda oriundos da tradicional, mas que romperam com o sindicalismo político vigente no pré-64, todos com o objetivo de construir um sindicalismo autônomo, em oposição ao atrelamento das entidades sin- 
dicais às estruturas do Estado e, desse modo, exercerem uma nova prática, que propugnava a liberdade e autonomia sindicais, além de amplo direito de greve.

Desta forma, o sindicalismo cutista nasceu rejeitando as formas de conciliação de classe, defendendo - especialmente durante o período de sua formação ao longo da década de 1980 - uma ação sindical mais combativa nos embates dos trabalhadores com governos e patrões. Suas lideranças sindicais desejavam, também, o reconhecimento de seus direitos de organização sindical. Na esfera política, as reivindicações giravam em torno da luta pelo fim da ditadura, da democratização do país, por meio das eleições diretas para presidente, governador, etc, bem como da instauração de uma Assembleia Constituinte, que contemplasse os interesses e direitos da classe trabalhadora, com a completa eliminação das leis de exceção.

O perfil desta liderança sindical foi forjado em nova prática, quer dentro dos sindicatos, piquetes, assembleias e passeatas, nas ações de diretas e ocupações dos locais de trabalho, nas greves parciais e gerais e diversas iniciativas que a luta sindical e política do movimento operário logra construir para resistir e lutar em seu cotidiano.

Essa associação entre distintas variantes do sindicalismo de classe partia de uma concepção de unidade concreta que, inclusive, esteve presente no próprio nome da Central, cujo conteúdo político-ideológico é o seguinte: “a ideia de única, [que] ficou no nome da Central, vem da concepção reinante no movimento sindical que as formas de organização e representação dos trabalhadores tinham que expressar, sempre, a unidade inquebrantável da classe" (Giannotti e Lopes Neto, 1991, p. 23).

A década de 1980 foi, então, um período especial das lutas sindicais e sociais: um amplo ciclo de greves, locais e gerais, desencadeado pelos operários industriais, assalariados rurais, assalariados médios, num amplo e denso movimento que se caracterizou pela existência de greves gerais por categoria (como as dos Bancários em 1995), greves com ocupação de fábricas (como a da General Motors em São José dos Campos em 1985 e a da Companhia Siderúrgica Nacional em Volta Redonda em 1989), bem como com o desencadeamento de greves gerais de âmbito nacional, como a de março de 1989, talvez a mais expressiva de todas as greves gerais desta década (Antunes e Santana, 2014; Antunes, 1995). Vale recordar que o número de greves foi extremamente significativo durante todo o período, sendo que, no mundo rural, houve significativo avanço do sindicalismo, possibilitando a retomada da organização sindical dos trabalhadores, o que, por certo, influenciou as ações que levaram ao nascimento do Movimento dos Trabalhadores Sem-Terra (MST), em 1984.

A partir de 1990, entretanto, a conjuntura econômica e política se transformou, com a vitória de Collor e início de seu governo, seguido depois pelo de FHC, criando as condições para que as políticas de corte neoliberal se desenvolvessem com intensidade. O setor produtivo estatal foi em grande medida privatizado (siderurgia, telecomunicações, energia elétrica, bancos, etc.), o que alterou o tripé existente entre capital nacional, estrangeiro e estatal, que comandou o padrão de desenvolvimento capitalista existente no Brasil desde a emergência do Varguismo, ampliando-se a internacionalização da nossa economia.

A fusão entre neoliberalismo e reestruturação produtiva, dentro de um universo conduzido pelo capitalismo financeiro, gerou profundas transformações no mundo do trabalho, afetando, em especial, o sindicalismo. Informalidade, flexibilização e terceirização passam a ser imperativos empresariais (Silva, 2009; Cardoso, 2003; Alves, 2000; Antunes, 1995; Druck, 1999). No apogeu da era da financeirização, do avanço técnico-científico -informacional, do mundo digital onde tempo e espaço se convulsionam, o Brasil vivenciou mutações fortes no mundo do trabalho, alterando sua morfologia, na qual a informalidade, a precarização e o desemprego ampliavam-se 
intensamente (Antunes e Santana, 2014; Santana, 2011; Souza, 2002; Galvão, 2002; J. Rodrigues, 1997; Antunes, 1995).

É nesta quadra histórica, na virada dos anos 1980 para década de 1990, isto é, na passagem do $3^{\circ}$ CONCUT (1988) para o $4^{\circ} \mathrm{CON}$ CUT (1991), que mudanças substanciais ocorreram no sindicalismo cutista, demarcando a consolidação de uma prática sindical que sempre esteve presente, ainda que em menor escala, no seu interior, mas que, até aquele momento, não tinha se tornado o centro da atividade sindical da CUT. Assim, pouco a pouco, a conduta propositiva e seu corolário, a negociação, passaram ao centro da orientação política da Central. Vale ressaltar, contudo, que a denominada fase movimentista ${ }^{2}$ já trazia embutida a característica que buscava a negociação. Combinavam-se movimentação, confronto e prática negocial na ação sindical, mas a ênfase gradativamente passava da confrontação para aquela que vai ser tonar dominante na década de 1990 (Silva, 2008; J. Rodrigues, 1997).

Esta "nova" práxis sindical tinha - e ainda tem- na negociação seu instrumento de ação predominante e acentua a propositura de que não bastava ao sindicalismo assumir tão somente uma conduta de rejeição às iniciativas dos patrões e governos, mas procurava, frente aos dilemas enfrentados pelos trabalhadores, จे construir alternativas "propositivas" consideФं radas mais viáveis e realistas. Rejeitando fortemente em sua prática a estratégia conduzida co durante a década de oitenta, a CUT passava a defender e praticar um sindicalismo modein rado, resultado a um só tempo das diretrizes is político-ideológicas da tendência hegemôni\& ca no seu interior, a Articulação Sindical - e

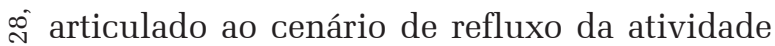
$\therefore$ sindical durante este período, tanto no âmbito internacional quanto no Brasil.

Segundo Iram Jácome Rodrigues (1997), as mudanças no sindicalismo cutista tive-

${ }^{2}$ Fase movimentista refere-se à prática sindical que prioriza os piquetes, assembleias, caminhadas, manifestações de rua e nas empresas etc. ram seu momento de maior expressão no $3^{\circ}$ CONCUT (1988), ${ }^{3}$ pois "simbolicamente, esse encontro significou o fim da fase heroica da construção da CUT e tudo que ela representava para uma parte da militância cutista” (Rodrigues, 1997, p. 117). A tese do fim da "fase heroica” fundamentava-se na concepção de que, nos primeiros momentos de criação, dada a necessidade de adquirir maior legitimidade junto às suas bases, haveria maior disposição em desencadear lutas e estratégias sindicais mais radicalizadas, ofensivas ou confrontacionistas, informadas de modo acentuado pelo ethos socialista. Desta forma, os caminhos trilhados pelo sindicalismo propugnado pela CUT, do momento de sua fundação ao seu $3^{\circ}$ Congresso, que ocorreu em 1988, "representou o período de sua construção e afirmação, cuja fase mais movimentista, libertária, socialista e de confrontação, enfim, heroica encerra-se com o III CONCUT” (Rodrigues, 1997, p.118).

Com esta mudança no perfil da ação e dos ativistas sindicais no interior da CUT, que ocorreu a partir do $3^{\circ}$ CONCUT, as práticas de maior confrontação e mais combativas começaram a dar lugar a um padrão de ação sindical mais pragmático e negocial; ${ }^{4}$ numa palavra, mais "propositivo" e negociador da entidade e da liderança sindical, como pode ser observado nestas passagens das Resoluções da $5^{\text {a }}$ Plenária Nacional da CUT:

O principal objetivo de nossa estrutura vertical deve ser a superação do fracionamento e pulverização resultante do atual sistema de organização e negociação por categoria, que divide os trabalhadores e dificulta o enfrentamento das questões já apontadas, além de preservar a interferência do Estado. Essa

${ }^{3}$ Alguns analistas têm sublinhado que a mudança ocorrida na forma de atuação política da Central foi decorrência da conquista da maioria interna, alcançada artificialmente pela Articulação Sindical, através das alterações nos estatutos da Central (Souza, 2002; Antunes, 1995; Costa, 1995). Houve uma drástica redução do número de delegados credenciados e escolhidos pelas bases e um aumento considerável no número de entidades.

4 “a) Vigência das atuais convenções e acordos coletivos de trabalho por tempo indeterminado, somente podendo ser alterado mediante futura negociação da qual participe a entidade sindical que o assinou ou seu sucessor" (Resoluções da $7^{\text {a }}$ Plenária Nacional Zumbi dos Palmares. CUT, 1995, p.24). 
estrutura é o elemento central do novo modelo sindical que estamos construindo e fundamental para o sucesso de nosso projeto sindical e político (CUT, 1992, p. 32).

Ou ainda,

Na situação em que vivemos hoje no Brasil e por tudo o que pudemos concluir de várias experiências de negociação, é necessário que o processo de negociação dos contratos (e convenção etc.) de trabalho permaneçam como processo de negociação e contratação no nível de categorias, ou seja, interempresas, e controlado pelo sindicato (CUT, 1992, p. 73).

É preciso salientar, entretanto, que as ações de caráter mais combativas e de confrontação parecem não estar somente associadas à fase de formação, isto é, vinculadas à sua origem, mas decorrem, em boa medida, da conjuntura política e da situação socioeconômica de cada momento. Por isso parece possível, também, supor que não existiria nenhuma garantia social e política de que, com o agravamento da situação socioeconômica dos trabalhadores, a CUT não voltaria a basear sua ação numa conduta política que recuperaria, mais acentuadamente, a linha da confrontação, em resposta à própria pressão da classe trabalhadora, como se pode presenciar embrionariamente na atual luta contra o PL 4330, em 2015, que amplia a terceirização também para as atividades-fim. Exemplos neste sentido apareceram, também, entre as categorias mais organizadas do sindicalismo brasileiro que, dadas as condições objetivas que os trabalhadores e trabalhadoras experimentaram, as permitiram questionar e levar adiante ações político-sindicais mais ofensivas do que aquelas desejadas pelas direções sindicais dominantes (Silva, 2008). ${ }^{5}$

Na década de 1990, justamente quando se acentuavam estas novas tendências, o novo sin-

${ }^{5}$ Vários exemplos neste sentido podem ser encontrados entre as diversas categorias presentes no sindicalismo cutista. Os bancários da cidade de São Paulo, cujo sindicato é controlado pela mesma corrente que detém a hegemonia na CUT, por meio da ação da oposição sindical e pressão dos trabalhadores de base, levaram adiante movimentos grevistas nacionais, em claro confronto com a orientação que privilegia a moderação. Outras categorias também têm seguido esse mesmo posicionamento, como professores, metalúrgicos, petroleiros, trabalhadores rurais etc. dicalismo foi confrontado por um contexto ainda adverso, iniciado com a vitória (e posse) de Collor. Conforme Antunes e Santana (2014) indicam, a forte pressão interna e externa imposta pelos capitais, objetivando avançar a reestruturação produtiva, a financeirização da economia e a livre circulação dos capitais, as privatizações do setor produtivo estatal, a flexibilização da legislação trabalhista, em suma, a pressão para uma nova inserção do Brasil na nova divisão internacional do trabalho sob a hegemonia neoliberal e financeira, tudo isso, ocorrendo simultaneamente e com forte intensidade, afetou intensamente o Brasil. Com o impeachment de Collor, o interregno Itamar Franco e a eleição de Fernando Henrique em 1994 (depois reeleito em 1998), o mundo produtivo no país foi profundamente alterado. As práticas da desregulamentação, flexibilização, privatização, desindustrialização ampliaram-se, assim como a informalidade, terceirização, subempregado e o desemprego (Antunes; Santana, 2014).

O sindicalismo da CUT, mais propenso à negociação, em um momento sindical novo, pautado pela existência de centrais sindicais diferenciadas e dificultado pelo advento da Força Sindical, criada em 1991 e que passou a disputar fortemente os espaços políticos e sindicais próprios de um sindicalismo mais negocial, fez com que a CUT, sob hegemonia da Articulação Sindical, respondesse avançando na alternativa mais contratualista e propositiva, oferecendo-se como alternativa sindical factível frente ao neoliberalismo. Ainda segundo os autores acima, a "defesa da redução dos tributos à indústria automobilística, como forma de dinamizar a indústria automotiva e com isso preservar empregos; a política de incentivo às "câmaras setoriais", espaço policlassista de negociação; as constantes participações em outros fóruns e espaços de negociação tripartites, distanciavam cada vez mais a CUT de seus valores fundacionais" (Antunes; Santana, 2014, p. 137). E acrescentam: "As políticas de 'convênios', 'apoios financeiros', 'parcerias' com a socialdemocracia sindical, especialmente 
européia, levada a cabo amplamente por duas décadas, também acabaram reorientando o “novo sindicalismo”, ajudando a arrefecer sua postura mais classista ao valorizar mais enfaticamente os espaços institucionalizados, as máquinas sindicais hierarquizadas e burocratizadas" (idem, p. 137).

$\mathrm{Na}$ impossibilidade de desenvolver as ações daquele período, foi emblemática a greve dos trabalhadores petroleiros em 1995, que se constituiu no primeiro combate aberto à política neoliberal de FHC. Essa greve configurou, entretanto, uma nítida divisão no interior da CUT que, mais próxima das políticas de concertação e negociação, não foi capaz de oferecer uma solidariedade efetiva e profunda aos petroleiros.

A CUT já não se apresentava mais como a herdeira das lutas sindicais pela autonomia e independência frente ao estado e ao patronato, mas, cada vez mais, ao longo dessa década, assemelhava-se a um sindicalismo institucionalizado, verticalizado, hierarquizado, que se distanciava de sua década original. E, ao proceder desse modo, com essa nova pragmática, ajudava a abrir caminho para a ascensão do Partido dos Trabalhadores ao poder, sem o peso de ser uma central sindical avessa à negociação e à moderação.

Após a vitória do Partido dos Trabalhaص dores - liderando uma frente considerada de ثे centro-esquerda - nas eleições presidenciais Фं de 2002 e a experiência do primeiro governo de Luiz Inácio Lula da Silva, com a manuten$\overbrace{}^{\infty}$ ção das políticas neoliberais do governo de ? FHC, o medo representado por um governo de is. esquerda capitaneado por aquele partido se ș desfez. O receio e a desconfiança não foram $\dot{\sim}$ completamente afastados, é verdade, mas per-

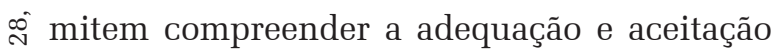

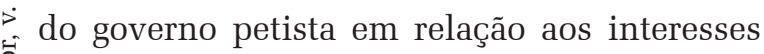
do grande capital e das distintas frações burguesas, particularmente aqueles representados pelo capital financeiro. Através da condução e do aprofundamento das principais políticas neoliberais anteriormente adotadas por FHC, o governo Lula e o Partido dos Trabalhadores já não provocam insegurança junto às classes dominantes. $^{6}$

A influência e o controle político do governo sobre vários movimentos sociais, bem como a orientação político-ideológica conduzida pela corrente hegemônica no interior da CUT constituíram-se em elementos importantes para se compreender as ações e dificuldades que diversos setores dos movimentos sociais, populares e sindicais mais à esquerda tiveram para enfrentar os governos e as políticas implementadas. Neste particular, a transformação da CUT, de Central sindical crítica e independente dos governos - como propugnam seus Estatutos, resoluções e plenárias em uma entidade fortemente afinada com as ações e políticas do governo Lula ${ }^{7}$ apenas serviu, mais uma vez, para desorientar e desorganizar o movimento sindical no combate e oposição ao ideário neoliberal, ainda que em sua nova variante social-liberal. Sua oscilação entre a adesão "crítica" ao ideário neoliberal ou social-liberal, recorrendo, entretanto, às ações e práticas sindicais um pouco mais combativas quando era imprescindível, deixou marcas profundas no sindicalismo cutista. ${ }^{8}$

A CUT foi, paulatinamente, deslocando o destinatário do seu discurso da "classe" para a "cidadania", sendo que suas ações priorizavam o caminho da luta por direitos aos cidadãos. O foco migrou para o combate aos diversos problemas enfrentados pela classe trabalhadora, tais como discriminação racial, de

${ }^{6}$ A eleição presidencial de 2006 talvez seja exemplar nesse sentido, pois a campanha petista baseou-se na manutenção da confiança e apoio político da burguesia; por isso a campanha não poderia deixar de trabalhar com ditados populares amplamente reiterados: "não troque o certo pelo duvidoso", numa clara demonstração de manutenção das políticas adotadas até aquele momento. O mesmo se repetiu com a eleição de Dilma em 2010 e, posteriormente, em 2014.

${ }^{7}$ Não deixa de ser sintomático dessa nova postura política adotada pela CUT, o fato de seu ex-presidente Luiz Marinho, componente da Articulação Sindical, ser alçado à condição de ministro do trabalho do governo Lula.

${ }^{8}$ Segundo Andréia Galvão: "A trajetória da CUT evidencia uma oscilação entre, de um lado, a assimilação de elementos do discurso neoliberal, que se revelam na elaboração de uma perspectiva propositiva e, de outro, a contraposição à política neoliberal, que tem permitido a reativação de uma prática sindical mais combativa” (GALVÃO, 2002, p. 109 - Grifo da autora). 
gênero, geracional, desemprego, qualificação, terceirização etc., associados sempre à ideia de conquista da cidadania, sem que os mesmos tivessem uma clara visão de classe. Operando um forte deslocamento dos interesses históricos da classe trabalhadora para a defesa abstrata da cidadania, a CUT distanciou-se, também, da construção (e até mesmo da defesa) de um projeto político alternativo à ordem social capitalista, que, cada vez mais, desaparecia das propostas e das ações da Central (Silva, 2008).

Parece não ser outro o sentido desta concepção: "a melhor perspectiva para o movimento sindical é comprometer-se com as lutas mais amplas. As políticas sociais devem estabelecer a relação entre sindicato e cidadania" (J. Nogueira, 1996, p. 212). Segundo a formulação da CUT:

Quando os trabalhadores brasileiros retomaram suas lutas e mobilizações no final da década de 1970, sob a ditadura militar, buscavam principalmente melhorar seu nível de vida e suas condições de trabalho. O passo seguinte foi avançar na luta pela conquista de direitos individuais e coletivos, ou seja, o direito ao pleno exercício da cidadania (CUT, 1992, p. 28).

Na VII Plenária Nacional (1995), a CUT reafirmou sua estratégia anterior no campo da educação, do emprego e da renda, da reestruturação produtiva etc. Essas bandeiras tinham como pressuposto a conquista e a manutenção de direitos sociais, como prerrogativa essencial para o exercício da "cidadania”:

A complexa realidade das relações de trabalho no país - agravada pelas medidas reativas do capital à crise econômica, pelo processo mundial de reordenação política e econômica, a globalização da economia, a organização dos blocos econômicos, acompanhados das recentes mudanças tecnológicas e organizacionais do trabalho na produção e nos serviços - introduz sérios desafios aos trabalhadores brasileiros que se somam às antigas lutas contra a exclusão social e pela conquista e manutenção dos direitos de cidadania (CUT, 1995, p. 32-33).

As iniciativas deliberadas, como, por exemplo, a conferência nacional em defesa da terra, do emprego e da cidadania, o dia nacional de luta por habitação e creches e o dia nacional da consciência negra, fundamentavamse na garantia da cidadania como instrumento de luta para combater o avanço das políticas neoliberais (CUT, 1996).

O embate político contra o racismo, por exemplo, também trilhou esse caminho, já que a luta se direcionava para o questionamento nos marcos do Estado de direito e da inserção dessa reivindicação no âmbito da política de direitos humanos. Foi esse o caminho construído politicamente para legitimar a luta pela ampliação da cidadania, sem que, é preciso enfatizar, a articulação destes temas fosse remetida à dimensão de classe (Silva, 2008).

Assim, a Central que nasce nos anos 1980, profundamente ancorada no universo do trabalho e nas lutas sindicais, consolidava sua transição para uma prática sindical moderada, aderindo, gradativamente, a uma concepção de defesa da cidadania desprovida de um componente acentuado de classe, além de atuar centralmente no espaço da negociação. Onde, vale recordar, ela não mais estava só, pois esse era, também, o espaço preferencial da Força Sindical. É dela que trataremos a seguir: como essas questões aparecem no interior da central sindical que se apresenta como a principal força política de oposição à CUT? Como respondem as lideranças da Força Sindical às transformações ocorridas na sociedade brasileira durante os anos 90? É o que trataremos no próximo item.

\section{A FORÇA SINDICAL: a pragmática neoliberal no interior do sindicalismo}

A Força Sindical foi fundada entre os dias 8, 9 e 10 de março de 1991, em São Paulo. ${ }^{9}$ Criada como uma nova proposta para o cenário sindical brasileiro, a Central dizia abarcar os mais variados setores do "movimento de luta

${ }^{9}$ Este item retoma pontos apresentados mais detalhadamente em Silva, 2008; 2013. 
dos trabalhadores Brasileiros". ${ }^{10}$ De acordo com Rodrigues e Cardoso (1993): "oficialmente, pelos documentos da secretaria da Força Sindical, teriam participado do congresso de fundação 1793 delegados, representando 783 sindicatos e federações, ao lado de 74 representantes internacionais" (Rodrigues; Cardoso, 1993, p. 13).

A principal finalidade da nova Central dizia respeito à direção do sindicalismo no quadro de redemocratização da sociedade brasileira: "as preocupações eram quanto ao rumo que o sindicalismo estava tomando, ficando para trás no processo de redemocratização do país, seja por causa do radicalismo estéril ou, por outro lado, por conformismo paralisante" (www.fsindical.org.br apud Silva, 2008).

Não resta dúvida de que a nova central surgiu disposta a estabelecer uma dupla distinção no sindicalismo brasileiro. De um lado, pretendia ser uma alternativa à CUT - definida como praticante de um "radicalismo inconsequente" - que não trazia resultados tangíveis aos trabalhadores. De outro lado, a Força Sindical buscava se diferenciar dos setores sindicais agrupados em torno da CGT de Joaquim de Andrade, Joaquinzão, caracterizados, aqui, como portadores de um conformismo paralisante. A pretensão da Força Sindical é

\begin{abstract}
Ser a central deste final de século pós-socialista, capaz de defender os interesses dos trabalhadores aqui e agora, sem relacionar as reivindicações imediatas à luta pelo socialismo, quer dizer, sem propostas utópicas que acabariam, na concepção da central, por induzir ao 'socialismo burocrático'. Desse ângulo, a Força Sindical marca, em seu discurso, um rompimento com as tradições corporativas, nacionalistas e socialistas das correntes mais militantes do sindicalismo brasileiro e parece mais adaptada às mudanças econômicas, sociais, políticas e culturais que estão marcando esse final de século (Rodrigues e Cardoso, 1993, p. 21).
\end{abstract}

Mas a pretensão da Força Sindical tinha de fato a finalidade de desarmar a resistência dos trabalhadores das investidas dos governos

${ }^{10}$ Para uma referência sumária à origem da Força Sindical, ver www.fsindical.org.br apud Silva, 2008) neoliberais: segundo Trópia, “o projeto da central era, originalmente, ambicioso: pretendia tornar-se a principal central sindical do País, derrotar as iniciativas progressistas e populares e bloquear a luta de resistência do movimento sindical ao modelo neoliberal" (Trópia, 2002, p. 160).

Por esse motivo, a bandeira veiculada pela nova Central era sintonizar o movimento sindical com a modernidade - "modernos somos, pois fomos quem primeiro teve a coragem de modificar a visão do sindicalismo e do trabalho em geral" (www.fsindical.org.br apud Silva, 2008) -, atualização essa que deveria, para construir uma central forte, "endurecer quando preciso mas também de saber negociar, [ser] autônoma, livre, pluralista, aberta ao debate interno e com a sociedade" (www. fsindical.org.br apud Silva, 2008).

A novidade trazida pela Força Sindical estava presente tanto em seu projeto político como na sua prática. A nova Central objetiva mudar a sociedade brasileira transformando a cultura sindical brasileira. Contudo, ao contrário da mudança perseguida por outros projetos sindicais - especialmente aqueles referentes às tradições de esquerda que almejavam mudar a sociedade em direção ao socialismo -, o caráter das mudanças propostas pela Força Sindical visava "lutar pelo capitalismo. A mudança se referiria ao conteúdo do capitalismo que existiria entre nós" (Rodrigues; Cardoso, 1993, p. 17).

Neste sentido, o caráter da transição brasileira não era do capitalismo para o socialismo (como apontam várias resoluções da CUT, com ênfase ao menos nos anos 1980), e sim, uma mudança entre um capitalismo selvagem para uma sociedade capitalista avançada, competitiva e moderna (Rodrigues e Cardoso, 1993). Sociedade essa que garantisse espaços de participação efetiva para os trabalhadores, reconhecendo-os como protagonistas das decisões, pois "era preciso dar aos trabalhadores o reconhecimento de que eles poderiam participar do processo, sentando às mesas de negociação 
e endurecendo quando necessário. Antes de tudo, que os trabalhadores fossem voz ativa dos novos tempos que viriam" (www.fsindical. org.br - Grifo nosso - apud Silva, 2008)

Para além do discurso apresentado, pode-se afirmar que a Força Sindical foi, desde logo, um desdobramento do sindicalismo de resultados. Este surgiu da articulação de duas trajetórias sindicais distintas, que, a partir da segunda metade da década de 1980, passaram a defender o mesmo projeto político. De um lado, o grupo de ativistas que tem na liderança de Luiz Antônio de Medeiros sua maior expressão; oriundo do PCB, este dirigente sindical foi para o Sindicato dos Metalúrgicos de São Paulo para concretizar uma nova forma de ação sindical (Nogueira, 1998). De outro, a liderança de Antônio Magri, dirigente que fez sua carreira política no Sindicato dos Eletricitários do Estado de São Paulo e era uma espécie de representante de uma corrente sindical de influência norte-americana, que convivia e se mesclava com o velho peleguismo brasileiro, da qual a Força Sindical foi também herdeira. (Antunes, 1995).

O ideário do sindicalismo de resultados combinava essa sua origem dúplice - ou tríplice - com a nova pragmática neoliberal, que expressava a concordância com a sociedade de mercado e o reconhecimento da vitória do capitalismo; sua ação sindical deveria buscar a melhoria das condições de trabalho, sem extrapolar este âmbito da melhoria da força de trabalho. Acrescentava, ainda, que não caberia aos sindicatos nenhuma interferência partidária, mas sim, uma ação e influência na esfera política. (Silva, 2008 e 2013; Antunes, 1995; Força Sindical, 1993; Rodrigues e Cardoso, 1993).

O processo de formação da Força Sindical combinava a rejeição ferrenha ao confronto, ao mesmo tempo em que as ações sindicais são estrategicamente calculadas para não ultrapassar a esfera da negociação. De fato, a greve era concebida como a última alternativa depois de esgotadas todas as possibilidades de negociação. Conforme sua indicação: "fracas- sada a negociação, as entidades de representação sindicais de trabalhadores podem utilizar o instrumento da greve, sendo que, nos casos de serviços essenciais, alguns procedimentos específicos deverão ser preservados" (Força Sindical, 1993, p. 524).

A fundação da nova Central representou, entretanto, consequências políticas profundas para o conjunto do sindicalismo brasileiro: "sob os auspícios do governo Collor, a Força Sindical aderiu a aspectos da plataforma neoliberal ao apoiar, de forma militante, as privatizações e a desregulamentação do mercado de trabalho" (Trópia, 2002, p. 159). Ela "foi propositivamente neoliberal. A central engajou-se, ofensivamente, no processo de implementação da política estatal neoliberal, contribuindo, ao mesmo tempo, com a disseminação ideológica do neoliberalismo" (Trópia, 2002, p. 165). É preciso sublinhar, ainda, que a nova Central, em sintonia com os governos federais ao longo da década de 1990, fez sistemática campanha contra a atuação do MST, chegando a criar a Força da Terra para combatê-lo e tentar se constituir - sem nenhuma efetividade - como alternativa entre os trabalhadores rurais (Idem, p. 165).

Sua pretensa despartidarização e ou desideologização do movimento sindical, tese defendida e enunciada frequentemente pelos seus dirigentes, escondia - e acentuava - de fato, uma maior ideologização do movimento, acirrando a polarização entre as duas principais centrais sindicais. (Antunes, 1995; Silva, 2008; 2013) Em verdade, apesar da afirmação reiterada de apartidarismo, a Força Sindical não era uma entidade que adotava o apoliticismo como conduta política; a atuação e as afirmações de sua maior liderança, Luiz Antônio de Medeiros, desfazem qualquer dúvida quanto a esse ponto: "eu jamais disse, em lugar algum, que sou apolítico. Eu faço política, que eu considero política sindical. Sou contra a partidarização do sindicato" (Medeiros, apud Rodrigues e Cardoso, 1993, p. 22.). E, mesmo essa pretensa ausência de partidarização não significa que a Central não assuma valores, 
visões de mundo etc. que estejam associadas a agrupamentos ou partidos políticos. Ao contrário, no seu principal documento até hoje publicado (Força Sindical, 1993), a Força Sindical deixava claro, por exemplo, que era a favor da redução da presença do Estado na economia. A mesma concepção que foi defendida e implementada por Collor e FHC durante a década de 1990. A propalada - mas nunca praticada - desideologização da ação sindical implicava, de fato, a subordinação da classe trabalhadora que a Central pretendia representar no universo ideológico da sociabilidade capitalista. Conforme indica Fredericio:

A pretensa ‘desideologização’ da práxis sindical, na verdade, significa uma clara aceitação da sociabilidade do mundo capitalista: os agentes sociais ficam reduzidos à condição de obstinados comerciantes que só almejam vender sua mercadoria pelo melhor preço. A obtenção de 'resultados' numa conjuntura recessiva, além de inviável, tem a função ideológica de manter o movimento operário entregue à dinâmica do mundo burguês sem formular um projeto político alternativo visando a redimir o mundo do trabalho do fetichismo mercantil. (Frederico, 1994, p. 73).

Assim, a nova central adotava, segundo Rodrigues e Cardoso (1993), os princípios do liberalismo ${ }^{11} \mathrm{com}$ a finalidade de aprofundar a sociedade dentro da qual seria reservado à classe trabalhadora, do ponto de vista político, ه to e, do ponto de vista econômico, o aumento da participação dos salários na renda nacional क (Silva, 2008; 2013; Rodrigues e Cardoso, 1993;) Por exemplo, ao tratar em seu documento-programa Um projeto para o Brasil: a proposta da $\therefore$ Força Sindical, a nova Central afirmava que a

No plano dos direitos sociais e trabalhistas, com

11 Não se encontra o termo liberalismo social nos documentos da Central, como sublinham Rodrigues e Cardoso (1993); todavia, tal orientação política e ideológica pode స్ ser concluída da concepção geral dos textos. Encontra-se - a valorização do pensamento liberal em passagens como

I esta: "as conquistas cristalizadas no pensamento democrá-

U tico liberal - como o voto direto e universal, a liberdade de

- imprensa, liberdade de produção e comércio, livre concor-

rência etc. - podem e devem ser preservadas no âmbito de

um direito que cada vez mais é sensível ao desequilíbrio

ङ de poder na sociedade” (Força Sindical, 1993, p. 113). duplo objetivo de integrar os setores mais carentes e marginalizados da população, minimamente, aos serviços de proteção social do Estado, e de conferir maiores garantias ao empregado na sua relação com o empregador (tanto do ponto de vista individual como coletivo). (Força Sindical, 1993, p. 32).

Em outros termos, a Constituição deveria garantir uma forma de regulação contratual entre agentes que compram e vendem mercadorias, sempre no sentido de valorizar o preço da mercadoria-força de trabalho. No plano das liberdades individuais e políticas, o documento defende que a Constituição deveria garantir "a consolidação dos direitos civis e políticos do cidadão", impondo "restrições mínimas à formação e ao funcionamento dos partidos políticos" (Força Sindical, 1993, p. 32; Silva, 2008). E foi, também, dentro deste universo que a Central elaborou sua concepção de cidadania. Cidadão, para a Força Sindical, era um indivíduo portador de direitos, cidadão que é, antes de tudo, produtor, consumidor e eleitor. A concepção de cidadania que aparecia em seus documentos se referia ao padrão normativo e institucional, que garantia aos indivíduos as liberdades políticas e sociais, além do gozo de direitos.

Portanto, cidadão, aqui, diz respeito ao indivíduo que é capaz de produzir e consumir, sendo útil na esfera econômica. E, enfeixando o círculo da matriz de fundo neoliberal, ser cidadão é ter o direito de votar, o que significaria exercer participação política nos órgãos e decisões do Estado através do processo eleitoral. Como se pode depreender do texto abaixo:

Não basta, nesse sentido, estimular práticas de participação, mas estabelecer as condições institucionais para que a vontade organizada dos cidadãos - entendidos como produtores, consumidores e eleitores - interfira de modo importante nas grandes decisões econômicas e políticas. (Força Sindical, 1993, p. 44). ${ }^{12}$

\footnotetext{
${ }^{12} \mathrm{Na}$ mesma direção aponta a passagem a seguir: "O Estado haverá de ser menor e descentralizado. Na administração de interesses locais imediatos, por exemplo, o Estado deve ser auxiliado pela ação participativa dos próprios cidadãos, na gestão e na defesa de seus interesses" (Força Sindical, 1993, p. 41).
} 
A Força Sindical concebia a reforma do Estado brasileiro, a reforma administrativa, a melhoria das condições de vida etc. como mecanismos políticos para realizar o desenvolvimento humano e social que permita o exercício da cidadania plena. O caráter "moderno do Estado" deveria resguardar as normas de relação entre os agentes sociais, impedindo que o mercado exercesse o papel de explorador e arena sob a qual age de modo pleno o poder econômico, pois o mercado deveria ser o espaço de criação de riquezas, do bem-estar e da qualidade de vida dos cidadãos:

Um Estado ‘moderno’ não é omisso, é um defensor intransigente das regras de interação dos agentes em sociedade. Particularmente em seu papel diante das atividades econômicas, cabe a ele garantir que o mercado não seja o universo da usurpação e do exercício puro e simples do poder econômico, mas o universo de criação de riquezas e do bem-estar dos cidadãos, entendidos como produtores e consumidores. (Força Sindical, 1993, p. 270).

Neste preciso sentido, a Força Sindical defendia que o trabalhador-cidadão fosse reconhecido como produtor e consumidor, efetivando uma espécie de cidadania mercantil que apenas poderia ser plena à medida que cumprisse os imperativos da lógica do mercado, no qual o trabalhador-cidadão fosse, simultaneamente, produtor e consumidor (Silva, 2008; 2013). ${ }^{13}$ É por isso que o objetivo de sua proposta de relação entre capital e trabalho era o de criar uma estrutura normativa, política e econômica que permitisse a administração do conflito existente. Com efeito, "o conflito entre capital e trabalho é dado natural entre esses dois atores sociais em uma economia de mercado. Desta forma, o importante é criar mecanismos que administrem esse conflito e não tentar reprimi-lo ou suprimi-lo" (Força Sindical, 1993, p. 517).

Coerente com sua concepção de integração das classes na sociedade capitalista,

${ }^{13}$ Não deixa de ser curioso como, apesar das origens bastante distintas e mesmo opostas, as proposições da Força Sindical passassem a contemplar, cada vez mais, certas similitudes com o movimento que vinha ocorrendo no interior da CUT em direção à conquista da cidadania. a Força Sindical incentivava a cooperação, em busca do objetivo comum, para "criar um ambiente de cooperação entre capital e trabalho que induza ao aumento da produtividade e das rendas reais dos trabalhadores" (Força Sindical, 1993, p. 517). O resultado, mais do que cooperação, foi na direção de aprofundar, através de sua ação sindical, os mecanismos de subordinação da classe trabalhadora aos imperativos da sociedade do mercado. (Silva, 2008; 2013; Antunes, 1995). Uma curiosa e imprevista aproximação com a CUT estava ocorrendo e, com ela começava a se gestar outra mutação no universo sindical. É dele que trataremos no último item. Mas, ainda outra mutação estava por ocorrer.

\section{RUMO AO SINDICALISMO NEGO- CIAL DE ESTADO?}

Cada uma ao seu modo, CUT e Força Sindical, para além das disputas e mesmo dos antagonismos que caracterizaram seus projetos iniciais, conforme procuramos evidenciar neste artigo, aproximavam-se ao defender uma política sindical voltada, centralmente, para a negociação e para a defesa da cidadania em detrimento (e não em sintonia) dos valores da classe trabalhadora. Suas diferenças, profundas no início, começaram lentamente a se desvanecer.

Vimos que a CUT foi muito mais ousada em suas propostas, especialmente durante a década de 1980, o período da confrontação, quando vinculou, explicitamente, a conquista de direitos sociais, a melhoria das condições de vida, como direito à saúde, por exemplo, à luta pela ampliação dos direitos sociais e políticos, além de reiterar em vários de seus encontros e documentos - inclusive no de fundação - a necessidade de lutar pela construção de uma sociedade socialista. Diferentemente, no caso da Força Sindical, a reivindicação pautava-se sempre pela ampliação de direitos políticos dentro de uma concepção liberal (de fato neoliberal), onde o aumento da participação política dos 
trabalhadores deveria ocorrer sempre dentro dos estritos limites das decisões no estado pela via da colaboração e da negociação, procurando colocar-se como alternativa dentro da ordem e claramente contra as posições da CUT:

As preocupações eram quanto ao rumo que o sindicalismo estava tomando, ficando para trás no processo de redemocratização do país, seja por causa de radicalismo estéril ou, por outro lado, por conformismo paralisante. Essas ações e inúmeras outras demonstraram sempre a capacidade de atuação da Força Sindical. Capacidade que logo predispôs à aglutinação de setores preocupados em defender e conquistar direitos efetivos para os trabalhadores (www.forçasindical.org.br apud Silva, 2008 - Grifo nosso).

Apesar das diferenças indicadas, entretanto, ao longo da década de 1990, a ação sindical de ambas as centrais orientou-se, como vimos, crescentemente para a defesa da cidadania, aceitando a existência conflitual, mas, em última instância, recusando o caminho da confrontação. Se este foi o eixo da ação da CUT ao longo de toda a década anterior, nos anos 1990, o centro de sua nova concepção, presente tanto em seus documentos, quanto em sua prática dominante, foi voltar-se para o avanço da cidadania.

Já a Força Sindical, que nascera em outro contexto, pautado pela recusa explícita à atuaç ção no universo da luta de classes, encontrava

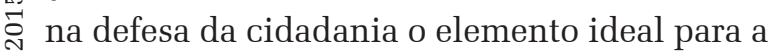
ญे sua proposição, uma vez que, desde suas origens, jamais se colocou na direção da conquisit ta de uma sociedade socialista. A CUT, ao contrário, fazendo o caminho inverso, foi, pouco is a pouco, abandonando qualquer discurso que is privilegiasse a prática de confrontação em be\& nefício da via predominante da negociação e ì da defesa do cidadão (Silva, 2008; 2013). ${ }^{14}$

${ }^{14}$ Como sublinha Saes (2003), o exercício da cidadania plena articulada com a concepção de classe significaria - acentuar as contradições da sociedade capitalista e das suas instituiçóes políticas, visto que a conquista de efe-

tivos direitos políticos e sociais situa-se além dos limites constituídos pela sociedade capitalista. É por isso que o autor afirma que "o processo de criação de direitos na sociedade capitalista é necessariamente conflituoso, embora não contraditório” (Saes, 2003, p. 20).
Força Sindical nasceu tendo, desde o início, um sentido pragmático e de atuação dentro do capitalismo "para melhorá-lo" - o que significava manter a classe trabalhadora, tanto política quanto ideologicamente, subordinada aos valores do capital -, para a CUT, a passagem de práticas com claro sentido de classe e de confrontação para ações sindicais mais moderadas e voltadas para a predominância propositiva (pela via da negociação) aprofundou-se ainda mais com a vitória eleitoral do Partido dos Trabalhadores. Tendo sua principal liderança forjada no interior do novo sindicalismo, a CUT ajudava, finalmente, o PT a conquistar a Presidência da República pelo voto direto. O que não se deu sem novas consequências. A nova pragmática sindical, inserida na lógica dominante da negociação, defrontava-se, agora, com um governo cujos membros eram, em boa medida, recolhidos também dentro da própria CUT, dada a forte simbiose que sempre existiu entre ambas. ${ }^{15}$

De sua parte, a Força Sindical somou-se à CUT e ambas tornaram-se partícipes do governo Lula. Atuaram conjuntamente, durante vários anos, como parceiras de governo, por certo com disputas pelos espaços existentes, mas exercitando uma convivência bastante diferente da década de 1990, onde, como vimos, CUT e Força Sindical pautavam-se por uma forte disputa, clara diferenciação e nítida conflagração. A defesa da negociação como caminho predominante e a conversão de suas programáticas, centradas na busca da "cidadania”, abriram caminho para que as diferenças

${ }^{15} \mathrm{O}$ quadro sindical já era também bastante distinto. Segundo Andréia Galvão: "Dez novas centrais sindicais surgiram a partir de 2004, somando-se às três centrais sindicais criadas nos anos 1980 e 1990 (CUT, CGTB/Central Geral dos Trabalhadores do Brasil e Força Sindical), dentre as quais destacamos: Conlutas (Coordenação National de Lutas), criada em 2004 e cuja denominação mudou para CSP-Conlutas em 2010; NCST (Nova Central Sindical de Trabalhadores), criada em 2005; Intersindical, criada em 2006; UGT (União Geral dos Trabalhadores) e a CTB (Central dos Trabalhadores e Trabalhadoras do Brasil), criadas em 2007 e CSB (Central dos Sindicatos Brasileiros), em 2012. Em 2008 a Intersindical se dividiu em: Intersindical - instrumento de luta e organização da classe trabalhadora e Intersindical - instrumento de luta, unidade de classe e construção de uma nova central. Esta última corrente fundou a Intersindical - Central da Classe Trabalhadora, em 2014. (Galvão, 2015, p. 4). 
fossem crescentemente reduzidas e ambas as centrais entrassem com força dentro do aparelho de estado. O novo sindicalismo chegava, finalmente, ao Estado, depois de tantos anos de luta pela autonomia e independência sindicais. A estrutura sindical atrelada ao estado - duramente combatida pela CUT em seus anos dourados e que sempre fora preservada pela Força Sindical - finalmente permitia que as duas principais centrais do país galgassem o topo do estado, sendo que a CUT, por sua própria vinculação estreita com o PT, era ainda mais intensa (Soares, 2005).

Participando de ministérios e secretarias nos âmbitos federal, estadual e municipal, elegendo-se para cargos de representação parlamentar, participando ativamente na gestão de fundos de pensão ${ }^{16}$ e dos conselhos de empresas estatais etc., o sindicalismo que propugnava a autonomia e a independência sindical frente ao estado, no caso da CUT, e o pretenso antiestatismo neoliberal propugnado pela Força Sindical, acomodaram-se muito bem nos aparatos burocrático-ministeriais dos governos do PT.

Mesclando traços da velha e persistente herança sindical peleguista, que a Força Sindical sempre conservou, com um burocratismo institucionalizado e verticalizado, que a CUT abraçou ao longo da década de 1990, ambas, entretanto, pautadas pelo ideário e pela pragmática da negociação e de defesa da cidadania, forjou-se o que, provocativamente, estamos denominando como sindicalismo negocial de estado.

A fértil engenharia da cooptação do governo Lula deslanchava vigorosamente: as centrais sindicais passaram a receber verbas estatais oriundas do FAT e, ao final da década de 2000, o governo, ampliando significativamente essa engenharia da cooptação, acentuava o controle estatal sobre os sindicatos, ao possibilitar que as centrais também passassem a receber o Imposto Sindical, criado na ditadura Vargas, ao final dos anos 1930, e que sempre ${ }^{16}$ Ver Soria e Silva, 2011; Bernardo e Pereira, 2008. fora combatido pela CUT. O sindicalismo de estado começava a ressuscitar, agora adicionado de um forte componente de proposição e negociação. O mundo negocial e a dependência estatal (política, ideologia e financeira) passaram, também, a fazer parte, ainda mais intensamente, do cotidiano daquele que, no passado recente, havia sido positivamente designado como novo sindicalismo.

Para onde foram os sindicatos? Esse é o tema proposto para este dossiê. Nossa resposta à hipótese apresentada no início deste artigo é que as últimas décadas parecem empurrar o novo sindicalismo em direção a uma esdrúxula combinação, síntese de, ao menos, três movimentos: a velha prática peleguista, a forte herança estatista e a forte influência do ideário neoliberal (ou social-liberal), impulsionada, ainda, pelo culto da negociação e defesa do cidadão. Vale dizer que cada um destes elementos pode ter prevalência em diferentes conjunturas. E esse Frankenstein que está sendo embrionariamente gestado, estamos denominando, provocativamente, como uma espécie de sindicalismo negocial de estado (Antunes, 2013). Se a profunda crise política, econômica e social que atinge o país neste ano de 2015 será capaz de afirmar ou infirmar a tendência, já é questão para outro artigo.

Recebido para publicação em 06 de junho de 2015
Aceito em 05 de agosto de 2015

\section{REFERÊNCIAS}

ALMEIDA, Maria H. O sindicato no Brasil: novos problemas, velhas estruturas. Debate e Crítica, São Paulo, n. 6, jul. 1975.

ALVES, Giovanni. O Novo (e precário) mundo do trabalho. São Paulo: Boitempo, 2000.

ARAÚJO. Angela. A construção do consentimento: corporativismo e trabalhadores nos anos trinta. São Paulo, Scritta, 1998.

ANTUNES, Ricardo. Classe operária, sindicatos e partido no Brasil. São Paulo: Cortez/Editora Ensaio, 1982. 1995. $O$ novo sindicalismo. Campinas: Editora Pontes, . A rebeldia do trabalho $(\mathrm{O}$ confronto operário no 
ABC Paulista: as greves de 1978/80). 2. ed. Campinas (SP): Editora da Unicamp, 1992.

Do novo sindicalismo ao sindicalismo negocial de Estado. Rio de Janeiro, Jornal dos Economistas, n. 268, novembro de 2011.

SANTANA, Marco Aurélio. Dilemas do "novo sindicalismo” no Brasil: ruptura e conservação. Califórnia, Latin American Perspectives, n. 5, vol. 41, 2014.

BERNARDO, João; PEREIRA, Luciano. Capitalismo Sindical. São Paulo: Ed. Xamã, 2008.

CARDOSO, Adalberto. A década neoliberal e a crise dos sindicatos no Brasil. São Paulo, Boitempo, 2003.

DRUCK, M. G. Terceirização: (des)fordizando a fábrica: um estudo crítico do complexo petroquímico. São Paulo: Boitempo, 1999.

FREDERICO, Celso. A Vanguarda operária. São Paulo: Edições Símbolos, 1979.

GALVÃO, A. Neoliberalismo e Reforma Trabalhista no Brasil. São Paulo: Ed. Revan/FAPESP, 2007.

GIANNOTTI, V.; NETO, S. L. CUT - ontem e hoje. Petrópolis, Vozes, 1991.

HUMPHREY, J. Fazendo o milagre. Petrópolis, Vozes/ Cebrap, 1982.

COSTA, Sílvio. Tendências e centrais sindicais - o movimento sindical de 1978 a 1994. São Paulo: Editora Anita Garibaldi: Editora da Universidade Católica de Goiás, 1995.

FREDERICO, Celso. Crise do socialismo e movimento operário. São Paulo: Cortez, 1994.

GALVÃO, Andréia. A CUT na encruzilhada: impactos do neoliberalismo sobre o movimento sindical combativo. In: Ideias - Revista do Instituto de Filosofia e Ciências Humanas - UNICAMP, CAMPINAS (SP), nº 9, 2002. p.105154.

A atuação política do sindicalismo brasileiro: dificuldades e contradições frente aos governos petistas, 2015 (ainda não publicado)

GIANNOTTI, Vito; LOPES NETO, Sebastião. CUT: ontem e hoje. São Paulo: Vozes, 1991. 120p.

MOREIRA, Fabrício Santos. Sindicalistas gestores: fundos de pensão e transformismo no sindicalismo bancário. 2015.

เ) Dissertação (Mestrado em Pós Graduação em Ciências

ㄱ Sociais) - Universidade Federal da Bahia.

ญ NOGUEIRA, Arnaldo. A modernização conservadora do sindicalismo brasileiro._Educ/FAPESP, São Paulo, 1998.

NOGUEIRA, João Carlos. A discriminação racial no $\infty$ trabalho sob a perspectiva sindical. In: MUNANGA, iิ Kabengele (org.). Estratégias e políticas de combate à 亡. discriminação. São Paulo: EDUSP/Estação Liberdade, is 1996. p. 211-221.

¿. RODRIGUES, Leôncio Martins. CUT: os militantes e a $\stackrel{10}{\wedge}$ ideologia. Rio de Janeiro: Paz e Terra, 1990.

म

; CARDOSO, Adalberto Moreira. Força sindical

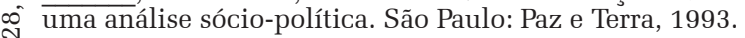

> RODRIGUES, Iram Jácome. Sindicalismo e política: a oิ trajetória da CUT. São Paulo: Scritta, 1997.

SAES, Décio Azevedo Marques de. Cidadania e capitalismo: uma crítica à concepção liberal de cidadania. Crítica Marxista, São Paulo, no 16, 2003. p. 9-38.

SANTANA, Marco. A. Entre a ruptura e a continuidade: visões da história do movimento sindical brasileiro. Revista Brasileira de Ciências Sociais, São Paulo, ANPOCS, n. $41,1999$.
Homens partidos: comunistas e sindicatos no Brasil. São Paulo/Rio de Janeiro: Unirio /Boitempo, Rio de Janeiro/São Paulo, 2001.

SILVA, Jair Batista da. Ação sindical, racismo e cidadania no Brasil. In: Antunes, Ricardo. (Org.). Riqueza e miséria do trabalho II. 1ed. São Paulo: Boitempo Editorial, 2013, v. 1 , p. 383-402.

Edufba, 2009

A perversão da experiência no trabalho. Salvador:

Racismo e sindicalismo: reconhecimento, redistribuição e ação política das centrais sindicais acerca do racismo no Brasil (1983-2002). 2008. Tese (Doutorado em Ciências Sociais) - Universidade Estadual de Campinas / Instituto de Filosofia e Ciências Humanas, Campinas, SP.

SOARES, José de Lima. Pt e a Cut nos Anos 90: encontros e desencontros de duas trajetórias. Brasília: Editora Fortium, 2005

SORIA E SILVA, Sidartha. Intersecção de classes: fundos de pensão e sindicalismo no Brasil. 2011. Tese (Doutorado em Sociologia). Universidade Estadual de Campinas Instituto de Filosofia e Ciências Humanas, Campinas, SP.

SOUZA, José dos Santos. Trabalho, educação e sindicalismo no Brasil: anos 90. Campinas, SP: Autores Associados, 2002.

Trabalho, qualificação e ação sindical no Brasil no limiar do século XXI: disputa de hegemonia ou consentimento ativo?. 2005. 340f. Tese (Pós-graduação em Sociologia) - Instituto de Filosofia e Ciências Humanas, UNICAMP, Campinas (SP).

TRÓPIA, Patrícia Vieira. A adesão da Força Sindical ao neoliberalismo. In: Ideias - Revista do Instituto de Filosofia e Ciências Humanas - UNICAMP, CAMPINAS (SP), no 9, 2002. p. 155-202.

VIANNA, Luiz W. Liberalismo e Sindicato no Brasil. Rio de Janeiro: Paz e Terra, 1976.

\section{DOCUMENTOS CONSULTADOS}

1) CUT. Resoluções do $3^{\circ}$ Congresso Nacional da CUT. Belo Horizonte: CUT, 1988.

2) CUT. Resoluções da $5^{a}$ Plenária Nacional da CUT. São Paulo: CUT, 1992.

3) CUT. Resoluções da $7^{a}$ Plenária Nacional da CUT. São Paulo: CUT, 1995.

4) CUT. Resoluções da $8^{a}$ Plenária Nacional da CUT. São Paulo: CUT, 1996.

5) CUT. Resoluções do $6^{\circ}$ Congresso Nacional da CUT. São Paulo: CUT, 1997.

6) FORÇA SINDICAL. Um projeto para o Brasil: a proposta da Força Sindical. São Paulo: Geração Editorial, 1993.

7) Força Sindical. História da Força. disponível em www. fsindical.org.br (acessado em julho de 2015).

\section{SITES CONSULTADOS}

www.cut.org.br

www.fsindical.org.br 
WHERE DID THE LABOR UNIONS GO? From a combative unionism to a negotiating unionism

\author{
Ricardo Antunes \\ Jair Batista da Silva
}

This article tries to answer the following question: where did the labor unions go? For such, we analyze the two main union centers: the Workers Union Center (CUT) and the Union Force (FS), regarding their ideals and the unionized actions. Our main hypothesis is that contemporary Brazilian unions, called new unionism, went through big transformations over more than three decades. These transformations significantly altered their practices and union concepts. This is especially apparent in its most important center, the CUT, a direct result of the new unionism, which distanced itself in actions from the so-called combative unionism, which clearly has a classist take, towards union actions that are more negotiating and aim to broaden citizenship spaces. To perform this analysis, our research focused on the main resolutions from Congress, assemblies, documents, and on studies that analyzed union practices over the last decades.

KeYwords: Union practices. Union centers. New unionism. Negotiating unionism. CUT. Union Force

\section{OÙ SONT DONC LES SYNDICATS? Du syndicalisme de confrontation au syndicalisme de négociation}

\author{
Ricardo Antunes \\ Jair Batista da Silva
}

Le but de cet article est d'indiquer des éléments capables de répondre à la question suivante : où sont donc les syndicats? À ces fins nous analysons les deux principaux syndicats du pays : la Centrale Unique des Travailleurs (CUT) et la Force Syndicale (FS), autant au niveau de leurs idées que dans le cadre de leurs actions syndicales respectives. Notre hypothèse principale est que le syndicalisme brésilien récent, appelé nouveau syndicat, a souffert d'importantes transformations pendant plus de trois décennies qui ont fini par modifier de manière significative leurs pratiques et leurs conceptions syndicales. Ce fut tout particulièrement le cas de son représentant le plus important, la CUT. C’est une conséquence immédiate du nouveau syndicalisme dont l'action s'est éloignée du dit syndicalisme militant, doté d'un caractère de classes très clair, pour aller vers des pratiques syndicales portant essentiellement sur des négociations visant à élargir les espaces de citoyenneté. Notre analyse est fondée sur les principales résolutions prises au cours des congrès, les sessions plénières, les documents et les recherches qui ont étudié les pratiques syndicales au cours des dernières décennies.

Mots-CLÉs: Action syndicale. Fédérations syndicales. Nouveau syndicalisme. Syndicalisme de négociation. CUT. Force Syndicale. 
ERRATA

Caderno CRH - Volume 28, Número 75, set./dez. 2015, p. 511-528, http://dx.doi.org/ 10.1590/S0103-49792015000300005 na página 511

onde se lia:

TRABALHADORES E SINDICALISMO NO BRASIL: para onde foram os sindicatos?

Leia-se:

"PARA ONDE FORAM OS SINDICATOS? Do sindicalismo de confronto ao sindicalismo negocial”

DOI: http://dx.doi.org/10.1590/S0103-49792015000300019 